\title{
Patient-Perceived Outcomes and Quality of Life in ALS
}

\author{
Zachary Simmons
}

Published online: 11 December 2014

(C) The American Society for Experimental NeuroTherapeutics, Inc. 2014

\begin{abstract}
A variety of outcome measures are used in clinical practice and in research to assess patients with amyotrophic lateral sclerosis (ALS). However, there may be discordance between traditional outcome measures such as strength and physical function, and patient-perceived measures of wellbeing. One such self-perceived measure, reflecting the patient's view, is quality of life (QOL). QOL in patients with severe medical disorder is often underestimated by others. Patients with ALS often have high QOL, and this may persist throughout the disease due to shifting expectations and to reprioritization of factors contributing to QOL. QOL instruments can measure health-related QOL (HRQOL) or global QOL, and can be generic or disease-specific. HRQOL refers primarily to physical and mental health. Global QOL is much broader, and is also determined by non-health-related factors. The choice of a QOL instrument depends on whether the setting is routine patient care or clinical research, whether or not the outcome of a specific intervention is being assessed, and upon the expected efficacy or toxicity of the intervention. Global QOL instruments are best for individual clinical patient care or for comparing groups. HRQOL or a combination of HRQOL and global QOL instruments are most appropriate for assessing specific interventions.
\end{abstract}

Key Words Amyotrophic lateral sclerosis · Quality of life · Health-related quality of life $\cdot$ Psychological health $\cdot$ Outcome measures

\footnotetext{
Z. Simmons $(\bowtie)$

Department of Neurology, Penn State Hershey Medical Center, EC

037, Hershey, PA 17033, USA

e-mail: zsimmons@hmc.psu.edu
}

\section{Introduction: Why Patient-Perceived Outcomes Matter}

A variety of outcome measures are used to assess patients with ALS in clinical practice and in research. Common measures in routine clinical care include limb strength as measured by manual muscle testing or hand-held dynamometry, physical function as measured by the ALS Functional Rating Scale (ALSFRS) and its revised version (ALSFRS-R) [1, 2], and respiratory parameters such as forced vital capacity, maximum inspiratory pressure and sniff nasal inspiratory force. Research outcome measures have varied widely, due to the lack of a specific biomarker to measure ALS disease progression. The most common have been survival, rate of change in strength, and rate of change in function [3]. However, there is not always concordance between traditional outcome measures and patient-perceived measures of well-being. This is not unique to ALS, but has been found in many neurological and non-neurological diseases [4-7].

To date, only one drug, riluzole, has been shown to be effective in altering the natural history of ALS [8,9], and it is not clear if the very modest average benefit conferred by riluzole is perceived by patients as being meaningful. As the field moves forward, it will be important to determine whether the benefits of new therapies are meaningful to patients. A cure for ALS would, of course, be meaningful to the individuals being treated. But current drug trials for ALS are geared toward extending survival, slowing rate of progression of weakness, or slowing loss of function. The concept of "clinically meaningful" changes in ALS measures is just beginning to be studied [10]. A different, or at least complementary, way to assess the perceived value of a new therapy is to measure its impact on quality of life (QOL), as perceived by the patient. For drug trials, a critical question is whether the benefits outweigh the costs. Ignoring the economic implications, the costs can be thought of primarily as being of two types: 1) adverse effects of medications, and 2) the physical and 
psychological costs of remaining alive longer with a progressive, degenerative neurological condition. One can imagine scenarios in which an experimental drug prolonged survival or slowed rate of disease progression, but with profound fatigue, or persistent nausea, or an increase in pain and cramping. Using "objective" clinical trial endpoints such as survival or rate of change in strength and function, such a treatment would be considered successful. However, from the patient's perspective, the treatment might be considered a failure if they deemed their QOL to be poorer and if this led them to question the value of the added survival time.

QOL must be considered not only in the context of therapeutic trials, but in standard clinical care as well. Noninvestigational clinical care measures for ALS are currently palliative, including the optimization of mobility and activities of daily living, nutrition, communication, respiratory function, psychological well-being, pseudobulbar affect, sialorrhea, pain, cramps, spasticity, fatigue, sleep, and end-of-life decisions $[11,12]$. It is important to assess whether our standard clinical management tools produce more benefits than costs. If we prolong a patient's life with a gastrostomy tube or with noninvasive ventilation (NIV), are we benefitting them, or subjecting them to more prolonged suffering as their disease inexorably progresses and they live for a longer time in a debilitated state? This is not a hypothetical consideration. Such questions arise regularly in ALS clinics around the world, posed by patients, caregivers, and health care professionals.

\section{Patient Perceptions vs. Those of Others}

QOL is a patient-perceived measure that must reflect the views of the patient. This is critical, because QOL in patients with severe medical disorders, including ALS, is often underestimated by others, including healthy individuals, caregivers, and health-care professionals [13-18]. This is not limited to perceptions of QOL, but to other patient-perceived measures. In one study, caregivers rated patients as having less energy and greater suffering than patients rated themselves as having [19]. Another study noted that healthy persons and caregivers estimated depression in patients with ALS to be present more frequently than was the case as judged by patients. The same study found that a wish for hastened death (assisted suicide or euthanasia) was lower in patients with ALS than what healthy subjects thought it would be [18]. In a study in which patients with ALS and their next of kin were asked to rate their own physical, general, and psychological well-being and that of the other on a visual analog scale ranging from very bad to very good, the next of kin rated both the general and psychological well-being of those with ALS lower than the patients rated themselves [20].

\section{Defining and Measuring QOL: General Concepts}

In order to use QOL measures to maximize the value of research protocols and to optimize clinical care for those with ALS, it is essential to understand the concept of QOL and to become familiar with the instruments that can facilitate its measurement. QOL instruments can be thought of as measuring health-related QOL (HRQOL) or global QOL, and as being generic (disease-agnostic) or disease-specific. HRQOL, also known as health status, refers to physical and mental health, whereas global QOL has many additional components. The World Health Organization has noted that QOL is broadly defined by nonmedical as well as medical factors, including “...psychological state, level of independence, social relationships, personal beliefs, and their relationship to salient features of the environment" [21]. Thus QOL is determined not only by items related to physical and mental health, but by a variety of non-health-related factors, including existential factors such as jobs, family, friends, spirituality, and other life circumstances [22]. Importantly, two individuals with the same health status may not (and often will not) have the same self-perceived QOL.

QOL is measured using specific instruments. The construct of QOL must be clear and specific for the instrument being used. Each instrument must have clearly defined areas (domains) that identify those factors that contribute to QOL. The clinician or investigator then can study how patients perceive these domains, and how the domains change over time, thereby using this information to maintain or improve QOL for patients and their families. While it is true that an inquiry into QOL can be made with a simple question asking the patient to rate his or her QOL on a 0-10 scale, such a simple approach will not provide the care team with the detailed understanding of the factors contributing to that individual's QOL that is necessary for designing or modifying interventions to help maintain or improve their QOL. Importantly, it also fails to provide the patient with a platform by which to perform a structured, item-by-item analysis of their QOL.

\section{Defining and Measuring QOL: Specific Instruments}

There is no consensus regarding the best instrument for measuring QOL in patients with ALS, or even which factors are most important in assessing QOL in these patients. As a result, there are many such instruments in use. QOL instruments may be generic (disease-agnostic) or disease-specific, and may measure HRQOL or global QOL (Table 1) [23, 24]. Early instruments used for ALS were the Sickness Impact Profile (SIP) [23] and the Short form-36 (SF-36) [24], both of which assess HRQOL. Because they are heavily weighted toward physical function, both inevitably decline with progression of 
Table 1 Classification of some of the major quality of life instruments relevant to ALS

\begin{tabular}{clc}
\hline & Generic & Disease-Specific \\
\hline $\begin{array}{cl}\text { Health- } \\
\text { Related }\end{array}$ & - Sickness Impact Profile (SIP) & - ALS Assessment Questionnaire-40 (ALSAQ-40) and ALSAQ-5 \\
Global & Short Form 36 & \\
& $\bullet$ WHOQOL-BREF & - ALS Specific Quality of Life Instrument (ALSSQOL) and \\
& McGill Quality of Life Questionnaire & ALSSQOL-R \\
& Schedule for the Evaluation of Individual QOL (SEIQoL) and & \\
& SEIQoL-DW & \\
\hline
\end{tabular}

WHOQOL-BREF=World Health Organization Quality of Life 26-item questionnaire

the disease $[25,26]$. Attempts at a broader measure of QOL have included the ALS Assessment Questionnaires (ALSAQ40 and ALSAQ-5), but these also are skewed toward measuring physical function, and decline as the patient with ALS weakens [27-29].

Pioneering work on a more global view of QOL was performed by the World Health Organization (WHO), which developed and validated 2 instruments for measuring QOL: the WHOQOL-100 [30] and the WHOQOL-BREF [31, 32]. The WHOQOL-100 is a 100 -item questionnaire that was developed in 15 field centers around the world. The WHOQOL-BREF is an abbreviated 26-item version of the WHOQOL-100. Four domains are assessed: physical (physical health and level of independence), psychological (including spirituality, religion, and personal beliefs), social relationships, and environment. WHOQOL instruments can be used in a variety of settings, and results are comparable across cultures.

Additional important work on global QOL assessment led to the development of the McGill QOL Questionnaire (MQOL) [33-35]. This is a non-disease-specific instrument developed in direct response to a perceived over-emphasis on the physical domain in existing QOL instruments. The MQOL places strong emphasis on the existential domain, such as meaning in life and perception of purpose, by asking subjects questions such as whether the past few days were a burden or a gift, or whether they perceive their lives as worthless or worthwhile. Using the MQOL, QOL in patients with ALS was found to be generally high, and not to change much over time [36, 37]. These studies also found that QOL in these patients depended not on strength or physical function, but on psychological and existential factors, and likely also on spiritual factors and support systems. Religion appeared to play a powerful role as well, particularly with disease progression [38, 39].

Additional insight into QOL in ALS came from studies using the Schedule for the Evaluation of Individual QOL (SEIQoL) and the Direct-Weighting version (SEIQoL-DW). These are non-disease specific instruments that are based on the concept that each individual's QOL is what he or she determines it to be, and that factors contributing to QOL should be individually selected [40-42]. In using these instruments, individuals are asked to identify areas (cues) that are most important to their QOL and to determine the relative importance of each cue to that individual's QOL. The cues chosen by ALS patients are far broader than physical strength and function. The cue category "Family/significant other" has been consistently one of the most common and most important as judged by patients with ALS. Religion, recreation, hobbies, friends, entertainment, leisure activities, and social life and relationships are consistently chosen by these patients as well. Health usually is not the most heavily weighted or most commonly chosen cue. As with the MQOL, SEIQoL scores in patients with ALS are relatively high, well-maintained over time, and independent of physical function [26, 43-46].

Despite their obvious strengths, both the MQOL and the SEIQoL have shortcomings. The MQOL questionnaire is not a disease-specific or individualized instrument, and so does not permit much insight into some aspects of QOL that are ALS-specific, such as loss of communication, or sialorrhea. The SEIQoL, while useful for measuring QOL of individuals, is of uncertain value for measuring QOL of groups [46]. Such limitations were the motivation for the development of the ALS-Specific Quality of Life Instrument (ALSSQOL) [47] and its shorter, revised version, the ALSSQOL-R [48]. These are ALS-specific global QOL instruments with 6 domains: Negative Emotion (anxiety, depression, and other measures of psychological morbidity); Interaction with people and the environment; Intimacy; Religiosity; Physical symptoms; and Bulbar function. Both the ALSSQOL and ALSSQOL-R have been found to be valid in large, multi-center studies for the assessment of overall QOL in patients with ALS. The ALSSQOL-R is available for use in the public domain free of charge. It contains 46 questions, making it challenging to complete for some patients during a routine clinical visit. A shorter version, the ALSSQOL-SF, has been developed and is undergoing multicenter validation.

\section{Response Shift}

The relatively high and stable overall QOL of individuals with ALS and other chronic diseases has been explained as a 
Response Shift, also known as a Frame Shift [44]. Response shift involves recalibration, reprioritization, and reconceptualization. Through these mechanisms, patients with serious illnesses experience changes in those factors that they perceive as being important to maintenance of QOL. That is, they recalibrate their expectations to more closely match reality [49-51]. In the case of individuals with ALS, as they become weaker, they experience a change in the factors that contribute most to their QOL from those which are dependent upon physical function to those which are not, such as family, friends, religious and spiritual supports, and the existential (meaning and purpose in life).

This shift appears to extend throughout the course of the disease. Case reports and small series beginning nearly two decades ago suggested that patients with ALS who had undergone tracheostomy/mechanical ventilation (TMV) could have a good QOL, and that this did not differ from those who did not require ventilatory support [52,53]. More recent, larger studies support this as well. One study of 34 patients with ALS or locked-in syndrome (27 with ALS, 7 with locked-in syndrome), compared 12 who were being supported by TMV with 22 who were not. QOL scores were not significantly different between the two groups [54]. Whether ventilation is planned or not also appears to make little difference. A study of 60 patients with ALS who underwent TMV assessed the results of the Life Satisfaction Inventory (an instrument that assesses overall QOL using 3 domains: Mood tone; Zest for Life; Congruence between desired and achieved goals), and found these patients to have scores that were not significantly different from patients with ALS who were not dependent on TMV. Thirteen were asked directly whether they would choose tracheostomy and mechanical ventilation again, and 11 said they would [55]. Similarly, when 32 patients with ALS and TMV were compared using the Profile of Mood States (domains for depression, fatigue, vigor, anger) and the Munich Quality of Life Dimensions List to 21 who were using noninvasive ventilation, no differences were found between the two groups. And, when asked directly, $81 \%$ of those with TMV indicated they would choose ventilation again and $81 \%$ would advise other patients to do the same [56].

\section{Major Factors Impacting QOL}

Knowledge of those factors that impact QOL enhances the value of QOL as a research outcome measure, and forms the basis for clinical management of patients. Many of these factors are themselves patient-perceived measures, reinforcing the importance of the patient's view in determining QOL. As expected, the QOL measures used to study the impact of various factors vary widely, consisting of a mixture of
HRQOL and global QOL instruments. The factors are discussed in detail below and summarized in Table 2 .

Psychological Health: Depression, Hopelessness, and Anxiety Psychological health is a broad concept, encompassing depression, hopelessness, anxiety, thoughts about the future, and helplessness/control. Although used infrequently as a research outcome measure in ALS studies, it is an important part of the clinical assessment, and is a key domain within QOL. As with overall global QOL, psychological health of patients with ALS does not necessarily decline as physical strength and function are lost [57-60]. This does not mean that good psychological health is necessarily present in those with ALS. Patients with ALS have been found to have, on average, poorer psychological health than the general population, characterized by psychological distress levels similar to those of psychiatric outpatients on measures such as anxiety, depression, and somatization [61]. We have found in our ALS clinic that $43 \%$ of our patients who completed the ALSSQOL-R scored sufficiently low on the Negative Emotion subscore to justify concern for depression (unpublished data). It is important for clinicians and researchers to be familiar with the key components of psychological health, including depression, hopelessness, and anxiety.

Widely varying rates of depression in patients with ALS have been reported, varying from $2 \%$ or less to at least $75 \%$, depending upon definitions of depression and measures used [62-66]. It is likely that approximately $10 \%$ of patients meet DSM criteria for major depression [57, 62, 67]. This does not appear to be due to physical weakness [17, 68]. Importantly, depression is associated with poor QOL in ALS as measured by the MQOL, and by the Quality of Life Index (a global QOL questionnaire that includes support and existential domains) $[65,69,70]$, and so should be sought and treated in these patients.

It is also important to identify hopelessness. In patients with ALS, it is associated with poor QOL, as measured on a global 6 point scale from "as good as it can be" to "very bad, horrible" [67]. It predicts suicidal intent and suicide better than depression [71, 72], and is specifically associated with consideration of assisted suicide by patients with ALS [73].

Anxiety, another component of psychological health, appears to be present in individuals with ALS at higher rates than in the general population [64, 74]. Prevalence in published studies has ranged from $8 \%$ to $26 \%$. One relatively recent study found high levels of state anxiety in $18.6 \%$, medium levels in $41.3 \%$, and found a relationship between anxiety and QOL [74] using the MQOL and the Satisfaction with Life Scale, another global QOL scale [75].

It has been pointed out that the literature about psychological issues in ALS is long on diagnosis and short on interventions. Considerable effort has been expended in exploring 
Table 2 Factors Impacting QOL (see text for details)

\begin{tabular}{|c|c|c|}
\hline Factor & QOL Measure & HRQOL vs. Global QOL \\
\hline \multicolumn{3}{|l|}{ Negative Impact on QOL } \\
\hline \multirow[t]{2}{*}{ Depression } & MQOL & Global QOL \\
\hline & QOLI & Global QOL \\
\hline Hopelessness & 6-point scale & Global QOL \\
\hline \multirow[t]{2}{*}{ Anxiety } & MQOL & Global QOL \\
\hline & SWLS & Global QOL \\
\hline Dysphagia & SWAL-QOL & HRQOL \\
\hline Fatigue & MQOL & Global QOL \\
\hline \multirow[t]{3}{*}{ Pain } & MQOL & Global QOL \\
\hline & QOLI & Global QOL \\
\hline & 6-point scale* & Global QOL \\
\hline \multirow[t]{2}{*}{ Pseudobulbar Affect } & SF-36 & HRQOL \\
\hline & Visual analog scale & Global QOL \\
\hline \multicolumn{3}{|l|}{ Positive Impact on QOL } \\
\hline Existential & MQOL & Global QOL \\
\hline Support & MQOL & Global QOL \\
\hline Religion/spirituality & MQOL & Global QOL \\
\hline Multidisciplinary Clinic & SF-36 & HRQOL \\
\hline AAC Device & SF-36 & HRQOL \\
\hline Coping Strategies & SF-36 & HRQOL \\
\hline \multicolumn{3}{|c|}{ Positive Impact on QOL by HRQOL Measures Only } \\
\hline \multirow[t]{2}{*}{ Noninvasive ventilation } & SF-36, SAQLI, CRDQ, ESS, PSQI, SSS & All HRQOL \\
\hline & ALSSQOL-R & Global QOL \\
\hline \multirow[t]{2}{*}{ Gastrostomy } & SF-36 & HRQOL \\
\hline & ALSSQOL-R & Global QOL \\
\hline
\end{tabular}

*There was no impact of pain on QOL when using this instrument

A AC $=$ augmentative and alternative communication; $\mathrm{CRDQ}=$ Chronic Respiratory Disease Questionnaire; ESS= Epworth Sleepiness Scale; HRQOL = Health-Related QOL; MCS=Mental Component Summary; MQOL=McGill QOL Questionnaire; PSQI $=$ Pittsburgh Sleep Quality Index; QOLI= Quality of Life Index; SAQLI= sleep apnea QOL index; SF-36= Short Form-36; SSS=Stanford Sleepiness Score; SWAL-QOL= Swallowing QOL Questionnaire is multifactorial, including muscle cramps, spasticity, immobility with resulting mechanical pain from inability to change position, and the development of joint contractures. A study using the MQOL and another using the Quality of Life Index (a global QOL questionnaire that includes support and existential domains) [69], found that pain and QOL were related to one another [70, 80]. In contrast, Ganzini et al. did not find a correlation between QOL and pain in patients with ALS, using a 6-point scale in which QOL was rated from "as good as it can be" to "very bad, horrible" [67].

Pseudobulbar Affect There are no studies of pseudobulbar affect (PBA) and QOL that focus exclusively on ALS. In a study of 265 patients with PBA, 19 of whom had ALS, QOL, as measured by a visual analog scale and by the mental health component of the SF-36, was negatively impacted by PBA [81].

Existential, Support, and Religion/Spirituality Early work on QOL in ALS using the MQOL demonstrated the role of existential factors, support systems, religion, and the possibility of spirituality in sustaining QOL, as discussed above [36-39]. 
Multidisciplinary Clinics A Dutch study comparing ALS multidisciplinary clinics to traditional care demonstrated higher levels of QOL in the SF-36 domains of social functioning and mental health in those who attended multidisciplinary clinics [82].

Augmentative and Alternative Communication (AAC) Devices An AAC device can improve or at least stabilize QOL in severely dysarthric ALS patients, as measured by the SF-36, particularly the mental health score [83].

Coping Strategies The Brief COPE instrument was used to assess coping strategies in patients with ALS whose HRQOL was measured using the SF-36. Coping strategies and the aspects of HRQOL to which they were found to be related were emotional support related to physical functioning, emotional support related to emotional role functioning, venting related to mental health, positive reframing related to mental health, and disengagement related to emotional role functioning [84].

Noninvasive Ventilation (NIV) NIV has been found to improve QOL in patients with ALS in several independent studies using a variety of HRQOL instruments including the SF-36 Mental Component Summary, SF-36 "Vitality" domain, Sleep Apnea QOL Index, Chronic Respiratory Disease Questionnaire, Epworth Sleepiness Scale, Pittsburgh Sleep Quality Index, and Stanford Sleepiness Score [85-89]. In contrast, no QOL benefit for NIV was found when using a global QOL measure, the ALSSQOL-R [90].

Gastrostomy Tubes Gastrostomy tubes resulted in improvement in QOL, as measured by a HRQOL scale, the SF-36, in 11/13 ALS patients (84.6\%) with dysphagia who had undergone tube placement [91]. However, no QOL benefit was found when using a global QOL measure, the ALSSQOL-R [90].

Interaction of Factors Recently it has been found that depression, anxiety, fatigue, and coping, as well as social withdrawal, all interact to influence QOL in patients with ALS, as measured by the WHOQOL-BREF instrument [92].

\section{Choosing a QOL Instrument}

There is no universal "best" instrument for measuring QOL in patients with ALS. The choice of instrument depends on whether one is assessing individuals or groups, and whether the goal is facilitating best clinical care or measuring research outcomes. Some general principles can help provide guidance for both clinical care and research use (Table 3).

In the standard clinical ALS care setting, instruments measuring global QOL will provide clinically useful information about the overall self-perceived well-being of a patient as determined by wide-ranging factors including physical, psychological, existential, religious, and financial among others. Such instruments include the WHOQOL-BREF, the MQOL, the SEIQoL and SEIQoL-DW, and the ALSSQOL and ALSSQOL-R. The assessment of individual domains or individual questions within a domain gives the health-care provider guidance regarding specific areas to target for intervention. This might include, for example, the use of an AAC device to improve communication, or discussions with friends or family about ways of providing additional support, or the provision of counseling to the patient to facilitate a response shift. In our ALS clinic, we request that patients complete an ALS-specific QOL instrument (the ALSSQOL-R) prior to each clinic visit. This is reviewed by the clinical team at the visit. Areas of concern are used as the basis for discussion with the patient and other clinical team members, for assessment, and for devising care plans with shared decision-making by the patient, caregiver, and ALS clinic team members.

When assessing the overall self-perceived QOL of groups of individuals with a particular illness, in order to compare them to healthy controls or to groups of individuals with other disorders, global QOL assessments once again are an appropriate means to determine how the group in question is faring. The WHOQOL-BREF, the MQOL or the ALSQOL and

Table 3 Best QOL Instruments for Specific Uses

\begin{tabular}{ll}
\hline Setting & Best QOL Instrument(s) \\
\hline Clinical Care & Global QOL: \\
& WHOQOL-BREF \\
& MQOL \\
& SEIQoL and SEIQoL-DW \\
& ALSSQOL-R \\
& Global QOL: \\
& WHOQOL-BREF \\
Comparisons of Groups & MQOL \\
& ALSSQOL-R \\
& HRQOL \\
Therapeutic Intervention & Specific for the outcome of the \\
& intervention \\
Powerful or Toxic & Global QOL and HRQOL specific for the \\
Therapeutic & outcome of the intervention \\
Intervention & \\
\hline
\end{tabular}

ALSSQOL-R=ALS-specific QOL Instrument - Revised; HRQOL= Health-related QOL; MQOL=McGill QOL Questionnaire; SEIQoL$\mathrm{DW}=$ Schedule for the evaluation of individual quality of life - direct weighting; WHOQOL-BREF $=$ World Health Organization Quality of Life 26-item questionnaire 
ALSSQOL-R would be appropriate instruments in this setting. The SEIQoL is less suitable for such use [46].

In contrast, when assessing the impact of a specific therapeutic intervention, global QOL instruments are likely to be insensitive, because the intervention in question targets only one of many factors affecting overall QOL. For example, NIV will improve sleep quality and may provide better daytime energy, and so may lead to a feeling of better physical wellbeing, but if at the same time that individual's family support is weakening, or he/she is losing intimacy with a partner, or if friends stop visiting, or if there are financial difficulties, then global QOL as perceived by the patient may not be improved in the interval following initiation of the intervention, or may even decline. This likely explains the failure of the ALSSQOL-R to identify improvements in QOL with NIV or gastrostomy tubes in patients with ALS, despite the improvement in HRQOL measures. A similar consideration arises for trials of pharmacologic agents with potential diseasemodifying properties. Thus, for a specific intervention, a HRQOL instrument usually is more suitable than a global QOL measure. The selection of the instrument should be driven by the goal of ensuring that it is the most appropriate one for measuring the impact of the chosen intervention on a specific, clinically relevant aspect of QOL.

For a potentially powerful or toxic therapeutic intervention, the impact may be best assessed using a combination of both a global and a HRQOL instrument. Thus, if the intervention is so powerful as to have a major positive impact that outweighs other mitigating factors in the patient's life, or outweighs anticipated side effects, then a global QOL instrument would provide evidence of the overall value of that intervention, while a HRQOL instrument would at the same time demonstrate the impact of that intervention on specific aspects of QOL. Pharmacologic interventions for ALS are not yet at this stage for either efficacy or toxicity, but future treatments may benefit from such a dual approach to assessing QOL of participants in clinical trials.

\section{Conclusions}

It should now be clear to the reader that QOL is not a simple construct with an agreed-upon scale that leads directly to a quantitative result with obvious immediate significance in the way that a temperature permits detection of a fever or an arterial blood gas measurement demonstrates hypoxemia. Because the assessment of QOL in a patient is an important part of a physician's role, and the impact on QOL is a key part of the investigator's evaluation of an intervention, care must be taken in choosing the most appropriate and informative QOL measure for each clinical or research use. An understanding of the heterogeneity of QOL and its domains permits the intelligent selection and thoughtful use of these instruments, and ultimately supports the ethical principles of beneficence and patient autonomy: doing good for the patients and research subjects entrusted to our care, while ensuring that such care is guided by, and follows, the wishes of these individuals.

Required Author Forms Disclosure forms provided by the authors are available with the online version of this article.

\section{References}

1. ALS CNTF Treatment Study (ACTS) Phase I-II Study Group. The amyotrophic lateral sclerosis functional rating scale. Arch Neurol 1996;53:141-147.

2. Cedarbaum JM, Stambler N, Malta E, et al. The ALSFRS-R: a revised ALS functional rating scale that incorporates assessments of respiratory function. J Neurol Sci 1999;169:13-21.

3. Lanka V, Cudkowicz M. Therapy development for ALS: lessons learned and path forward. Amyotroph Lateral Scler 2008;9:131-141.

4. Marks GB, Dunn SM, Woolcock AJ. A scale for the measurement of quality of life in adults with asthma. J Clin Epidemiol 1992;45:461472.

5. Ward MM. Clinical measures in rheumatoid arthritis: Which are most useful in assessing patients? J Rheumatol 1993;21:17-21.

6. Ruhland J, Shields R. The effects of a home exercise program on impairment and health-related quality of life in persons with chronic peripheral neuropathies. Phys Ther 1997;77:1026-1039.

7. Wang B, Gladman D, Urowitz M. Fatigue in lupus is not correlated with disease activity. J Rheumatol 1998;25:892-895.

8. Bensimon G, Lacomblez L, Meininger V, the ALS/Riluzole Study Group. A controlled trial of riluzole in amyotrophic lateral sclerosis. N Engl J Med 1994;330:585-591.

9. Lacomblez L, Bensimon G, Leign PN, Guillet P, Meininger V. Doseranging study of riluzole in amyotrophic lateral sclerosis. Lancet 1996;347:1425-1431.

10. McElhiney M, Rabkin JG, Goetz R, et al. Seeking a measure of clinically meaningful change in ALS. Amyotroph Lateral Scler Frontotemporal Degener 2014;15:398-405.

11. Simmons Z. Management strategies for patients with amyotrophic lateral sclerosis from diagnosis through death. Neurologist 2005;11: 257-270.

12. Simmons Z. Rehabilitation of motor neuron disease. In: Barnes M, Good D, eds. Neurorehabilitation. Handbook of Clinical Neurology (Michael Aminoff, series ed). Elsevier, Amsterdam, 2013;483-498.

13. Slevin ML, Plant H, Lynch D, et al. Who should measure the quality of life, the doctor or the patient? Br J Cancer 1988;57:109-112.

14. Gerhart KA, Koziol-McLain J, Lowenstein SR, et al. Quality of life following spinal cord injury: knowledge and attitudes of emergency care providers. Ann Emerg Med 1994;23:807-812.

15. Rothwell PM, McDowell Z, Wong CK, et al. Doctors and patients don't agree: cross sectional study of patients' and doctors' perceptions and assessments of disability in multiple sclerosis. BMJ 1997;314:1580-1583.

16. Trail M, Nelson ND, Van JN, Appel SH, Lai EC. A study comparing patients with amyotrophic lateral sclerosis and their caregivers on measures of quality of life, depression, and their attitudes toward treatment options. J Neurol Sci 2003;209:79-85.

17. Kubler A, Winter S, Ludolph AC, Hautzinger M, Birbaumer N. Severity of depressive symptoms and quality of life in patients with amyotrophic lateral sclerosis. Neurorehabil Neural Repair 2005;19: 182-193. 
18. Lule D, Ehlich B, Lang D, et al. Quality of life in fatal disease: the flawed judgement of the social environment. J Neurol 2013;260: 2836-2843.

19. Adelman EE, Albert SM, Rabkin JG, et al. Disparities in perceptions of distress and burden in ALS patients and family caregivers. Neurology 2004;62:1766-1770.

20. Olsson AG, Markhede I, Strang S, Persson LI. Well-being in patients with amyotrophic lateral sclerosis and their next of kin over time. Acta Neurol Scand 2010;121:244-250.

21. WHOQOL: Measuring Quality of Life. Geneva: World Health Organization; 1997.

22. Gill TM, Feinstein AR. A critical appraisal of the quality of qualityof-life measurements. JAMA 1994;272:619-626.

23. Bergner M, Bobbitt RA, Carter WB, Gilson BS. The Sickness Impact Profile: development and final revision of a health status measure. Med Care 1981;19:787-805.

24. Ware JE, Sherbourne CD. The MOS 36-item short-form health survey (SF-36). I. conceptual framework and item selection. Med Care 1992;30:473-483.

25. McGuire D, Garrison L, Armon C, et al. Relationship of the Tufts Quantitative Neuromuscular Examination (TQNE) and the Sickness Impact Profile (SIP) in measuring progression of ALS. Neurology 1996;46:1442-1444.

26. Neudert C, Wasner M, Borasio GD. Individual quality of life is not correlated with health-related quality of life or physical function in patients with amyotrophic lateral sclerosis. J Palliat Med 2004;7:551557.

27. Kiebert GM, Green C, Murphy C, et al. Patients' health-related quality of life and utilities associated with different stages of amyotrophic lateral sclerosis. J Neurol Sci 2001;191:87-93.

28. Jenkinson C, Fitzpatrick R. Reduced item set for the amyotrophic lateral sclerosis assessment questionnaire: development and validation of the ALSAQ-5. J Neurol Neurosurg Psychiatry 2001;70:7073 .

29. Green C, Kiebert G, Murphy C, et al. Patients' health-related qualityof-life and health state values for motor neuron disease/amyotrophic lateral sclerosis. Qual Life Res 2003;12:565-574.

30. The WHOQOL Group. The World Health Organization Quality of Life Assessment (WHOQOL): development and general psychometric properties. Soc Sci Med 1998;46 (12):1569-1585.

31. The WHOQOL Group. Development of the World Health Organization WHOQOL-BREF quality of life assessment. Psychol Med 1998;28:551-558.

32. Skevington SM, O'Connell KA. The World Health Organization's WHOQOL-BREF quality of life assessment: psychometric properties and results of the international field trial. A report from the QHOQOL group. Qual Life Res 2004;13:299-310.

33. Cohen SR, Hassan SA, Lapointe BJ, Mount BM. Quality of life in HIV disease as measured by the McGill Quality of Life questionnaire. AIDS 1996;10:1421-1427.

34. Cohen SR, Mount BM, Tomas JJN, Mount LF. Existential well-being is an important determinant of quality of life. Cancer 1996;77:576586.

35. Cohen SR, Mount BM, Bruera E, Provost M, Rowe J, Tong K. Validity of the McGill Quality of Life questionnaire in the palliative care setting: a multi-centre Canadian study demonstrating the importance of the existential domain. Palliat Med 1997;11:3-20.

36. Simmons Z, Bremer BA, Robbins RA, Walsh SM, Fischer S. Quality of life in ALS depends on factors other than strength and physical function. Neurology 2000;55:388-392.

37. Robbins RA, Simmons Z, Bremer BA, Walsh SM, Fischer S. Quality of Life in ALS is maintained as physical function declines. Neurology 2001;56:442-444.

38. Walsh SM, Bremer BA, Felgoise SH, Simmons Z. Religiousness is related to quality of life in patients with ALS. Neurology 2003;60: $1527-1529$.
39. Bremer BA, Simone A-L, Walsh S, Simmons Z, Felgoise SH. Factors supporting quality of life over time for individuals with amyotrophic lateral sclerosis: the role of positive self- perception and religiosity, Ann Behav Med 2004;28:119-125.

40. McGee HM, O’Boyle CA, Hickey A, Joyce CRB, O'Malley K. Assessing the quality of life of the individual: the SEIQoL with a healthy and a gastroenterology unit population. Psychol Med 1991;21:749-759.

41. Hickey AM, Bury G, O’Boyle CA, Bradley F, O’Reilly F, Shannon W. A new short form individual quality of life measure (SEIQoLDW): application in a cohort of individuals with HIV/AIDS. Br Med J 1996;313:29-33.

42. Hickey A, O'Boyle CA, McGee HM, Joyce CRB. The schedule for the evaluation of individual quality of life. In: Joyce CRB, McGee HM, O'Boyle CA, eds. Individual Quality of Life: Approaches to Conceptualisation and Assessment. Harwood Academic Publishers, The Netherlands, 1999, pp 119-133.

43. Neudert C, Wasner M, Borasio GD. Patients' assessment of quality of life instruments: a randomized study of SIP, SF-36 and SEIQoL-DW in patients with amyotrophic lateral sclerosis. J Neurol Sci 2001;191: 103-109.

44. Bromberg MB, Forshew DA. Comparison of instruments addressing quality of life in patients with ALS and their caregivers. Neurology 2002;58:320-322.

45. Goldstein LH, Atkins L, Leigh PN. Correlates of quality of life in people with motor neuron disease (MND). Amyotroph Lateral Scler Other Motor Neuron Disord 2002;3:123-129.

46. Felgoise SH, Stewart JL, Bremer BA, Walsh SM, Bromberg MB, Simmons Z. The SEIQoL-DW for assessing quality of life in ALS: strengths and limitations. Amyotroph Lateral Scler 2009;10:456462.

47. Simmons Z, Felgoise SH, Bremer BA, et al. The ALSSQOL: balancing physical and non-physical factors in assessing quality of life in ALS. Neurology 2006;67:1659-1664.

48. Simmons Z, Felgoise SH, Rodriguez JL, Walsh SM, Bremer BA, Stephens HE. Validation of a shorter ALS-specific quality of life instrument: the ALSSQOL-R. Neurology 2010;74 (suppl 2):A177A178.

49. Schwartz CE, Sprangers MA. Methodological approaches for assessing response shift in longitudinal health-related quality of life research. Soc Sci Med 1999;48:1531-1548.

50. Carr AJ, Gibson B, Robinson PG. Measuring quality of life: is quality of life determined by expectations or experience? Br Med J 2001;322:1240-1243.

51. Barclay R, Tate RB. Response shift recalibration and reprioritization in health-related quality of life was identified prospectively in older men with and without stroke. J Clin Epidemiol 2014;67:500-507.

52. Abramson N. Quality of life: who can make the judgment? Am J Med 1996;100:365-366.

53. McDonald ER, Hillel A, Wiedenfeld SA. Evaluation of the psychological status of ventilator-supported patients with ALS/MND. Palliat Med 1996;10:35-41.

54. Rousseau MC, Pietra S, Blaya J, Catala A. Quality of life of ALS and LIS patients with and without invasive mechanical ventilation. $\mathrm{J}$ Neurol 2011;258:1801-1804.

55. Vianello A, Arcaro G, Palmieri A, et al. Survival and quality of life after tracheostomy for acute respiratory failure in patients with amyotrophic lateral sclerosis. J Crit Care 2011;26:329 e7-14

56. Kaub-Wittemer D, von Steinbuchel N, Wasner M, et al. Quality of life and pychosocial issues in ventilated patients with amyotrophic lateral sclerosis and their caregivers. J Pain Symptom Manage 2003;26:890-896.

57. Rabkin JG, Albert SM, Del Bene ML, et al. Prevalence of depressive disorders and change over time in late-stage ALS. Neurology 2005;65:62-67. 
58. Wicks P, Abrahams S, Masia D, Hejda-Fordea S, Leigh PN, Goldstein LH. Prevalence of depression in a 12-month consecutive sample of patients with ALS. Eur J Neurol 2007; 14:993-1001.

59. McElhiney MC, Rabkin JG, Gordon PH, Goetz R, Mitsumoto H. Prevalence of fatigue and depression in ALS patients and change over time. J Neurol Neurosurg Psychiatry 2009;80:1146-1149.

60. Cupp J, Simmons Z, Berg A, Felgoise SH, Walsh SM, Stephens HE. Psychological health in patients with ALS is maintained as physical function declines. Amyotroph Lateral Scler 2011;12:290-296.

61. Felgoise SH, Chakraborty BH, Bond E, et al. Psychological morbidity in ALS: the importance of psychological assessment beyond depression alone. Amyotroph Lateral Scler 2010;11:351-358.

62. Ganzini L, Johnston WS, McFarland BH, Tolle SW, Lee MA. Attitudes of patients with amyotrophic lateral sclerosis and their caregivers toward assisted suicide. N Engl J Med 1998;339:967-973.

63. Moore MJ, Moore PB, Shaw PJ. Mood disturbances in motor neurone disease. J Neurol Sci 1998;160 (suppl 1): S53-S56. ;

64. Rabkin JG, Wagner GJ, Del Bene M. Resilience and distress among amyotrophic lateral sclerosis patients and caregivers. Psychosom Med 2000;62:271-279.

65. Lou J-S, Reeves A, Benice T, et al. Fatigue and depression are associated with poor quality of life in ALS. Neurology 2003;60: $122-123$.

66. Averill AJ, Kasarskis EJ, Severstrom SC. Psychological health in patients with amyotrophic lateral sclerosis. Amyotroph Lateral Scler 2007;8:243-254

67. Ganzini L, Johnston WS, Hoffman WF. Correlates of suffering in amyotrophic lateral sclerosis. Neurology 1999;52:1434-1440.

68. Gauthier A, Vignola A, Calvo A, et al. A longitudinal study of qualify of life and depression in ALS patient-caregiver couples. Neurology 2007;68:923-926.

69. Spitzer WO, Dobson AJ, Hall J, et al. Measuring the quality of life of cancer patients. J Chron Dis 1981;34:585-597.

70. Pizzimenti A, Aragona M, Onesti E, Inghilleri M. Depression, pain and quality of life in patients with amyotrophic lateral sclerosis: a cross-sectional study. Funct Neurol 2013;28:115-119.

71. Minkoff K, Bergman E, Beck AT, et al. Hopelessness, depression, and attempted suicide. Am J Psychiatry 1973;130:455-459.

72. Beck AT, Brown G, Berchick RJ, et al. Relationship between hopelessness and ultimate suicide: a replication with psychiatric outpatients. Am J Psychiatry 1990;147: 190-195.

73. Ganzini L, Silveira MJ, Johnston WS. Predictors and correlates of interest in assisted suicide in the final month of life among ALS patients in Oregon and Washington. J Pain Symptom Manage 2002;24:312-317.

74. Vignola A, Guzzo A, Calvo A, et al. Anxiety undermines quality of life in ALS patients and caregivers. Eur J Neurol 2008;15:12311236.

75. Diener E, Emmons RA, Larsen RJ, Griffin S. The satisfaction with life scale. J Pers Assess 1985;49:71-75.

76. Pagnini F, Simmons Z, Corbo M, Molinari E. Amyotrophic lateral sclerosis: time for research on psychological interventions? Amyotroph Lateral Scler 2012;13:416-417.
77. McHorney C, Robbins J, Lomax K, et al.: The SWAL-QOL and SWAL-CARE outcomes tool for oropharyngeal dysphagia in adults: III. Documentation of reliability and validity. Dysphagia 2002;17: 97-114

78. Paris G, Martinaud O, Petit A, et al. Oropharyngeal dysphagia in amyotrophic lateral sclerosis alters quality of life. J Oral Rehabil 2013;40:199-204.

79. Chio A, Canosa A, Gallo S, et al. Pain in amyotrophic lateral sclerosis: a population-based study. Eur J Neurol 2013;19:551-555.

80. Pagnini F, Lunetta C, Banfi P, et al. Pain in amyotrophic lateral sclerosis: a psychological perspective. Neurol Sci 2012;33:11931196.

81. Colamonico J, Formella A, Bradley W. Pseudobulbar affect: burden of illness in the USA. Adv Ther 2012;29:775-798.

82. Van den Berg JP, Kalmijn S, Lindeman E, et al. Multidisciplinary ALS care improves quality of life in patients with ALS. Neurology 2005;65:1264-1267.

83. Korner S, Siniawski M, Kollewe K, et al. Speech therapy and communication device: impact on quality of life and mood in patients with amyotrophic lateral sclerosis. Amyotroph Lateral Scler Frontotemporal Degener 2013;14:20-25.

84. Montel S, Albertini L, Spitz E. Coping strategies in relation to quality of life in amyotrophic lateral sclerosis. Muscle Nerve 2012;45:131-134.

85. Jackson CE, Rosenfeld J, Moore DH, et al. A preliminary evaluation of a prospective study of pulmonary function studies and symptoms of hypoventilation in ALS/MND patients. J Neurol Sci. 2001;191: 75-78.

86. Lyall RA, Donaldson N, Fleming T, et al. A prospective study of quality of life in ALS patients treated with non-invasive ventilation. Neurology 2001;57:153-156.

87. Bourke SC, Bullock RE, Williams TL, Shaw PJ, Gibson GJ. Noninvasive ventilation in ALS: indications and effect on quality of life. Neurology 2003;61:171-177.

88. Butz M, Wollinsky KH, Wiedemuth-Catrinescu U, et al. Longitudinal effects of non-invasive positive-pressure ventilation in patients with amyotrophic lateral sclerosis. Am J Phys Med Rehabil 2003;82:597-604.

89. Bourke SC, Tomlinson M, Williams TL, Bullock RE, Shaw PJ, Gibson GJ. Effects of non-invasive ventilation on survival and quality of life in patients with amyotrophic lateral sclerosis: a randomized controlled trial. Lancet Neurol 2006;5:140-147

90. Zamietra K, Lehman EB, Felgoise SH, Walsh SM, Stephens HE, Simmons, Z. Noninvasive ventilation and gastrostomy may not impact overall quality of life in patients with ALS. Amyotroph Lateral Scler 2012;13:55-58.

91. Korner S, Hendricks M, Kollewe K, et al. Weight loss, dysphagia and supplement intake in patients with amyotrophic lateral sclerosis (ALS): impact on quality of life and therapeutic options. BMC Neurology 2013;13:84.

92. Gibbons C, Thornton E, Ealing, J, et al. The impact of fatigue and psychosocial variables on quality of life for patients with motor neuron disease. Amyotroph Lateral Scler Frontotemp Degener 2013;14:537-545. 